\title{
1 Importance of Structural Makeup of Biopolymers for Organic Contaminant 2 Sorption
}

Xilong Wang and Baoshan Xing ${ }^{*}$

Department of Plant, Soil and Insect Sciences, University of Massachusetts, Amherst, MA 01003

\section{Supporting Information}

TABLE S1. Selected Physicochemical Properties of the Chemicals Used in This Study

$\begin{array}{llcccccc}\text { Chemicals } & \text { Abbreviation } & \begin{array}{c}\text { MW } \\ (\mathrm{g} / \mathrm{mol})\end{array} & \log K_{\mathrm{ow}} & \begin{array}{c}S_{\mathrm{w}} \\ (\mathrm{mg} / \mathrm{L})\end{array} & \begin{array}{c}\text { Density } \\ \left(\mathrm{g} / \mathrm{cm}^{3}\right)\end{array} & \begin{array}{c}\text { MV } \\ \left(\AA^{3}\right)\end{array} & \mathrm{p} K a \\ \text { Pyrene } & \text { Pyrene } & 202.3 & 5.13 & 0.135 & 1.271 & 186.0 & \\ \text { Phenanthrene } & \text { Phen } & 178.2 & 4.46 & 1.15 & 1.063 & 169.5 & \\ \text { Naphthalene } & \text { Naph } & 128.2 & 3.29 & 31.02 & 0.997 & 126.9 & \\ \text { 1-naphthol } & \text { 1-Naph } & 144.2 & 2.70 & 866 & 1.10 & 96.6 & 9.34\end{array}$

MW: molecular weight; $K_{\text {ow }}$ : octanol-water partition coefficient; $S_{\mathrm{w}}$ : aqueous solubility; MV: molecular volume; $\mathrm{pKa}$ : negatively log-transformed acid dissociation constant. All data are taken from Wang et al. (1).

10

11

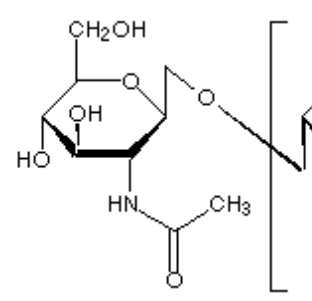

Chitin

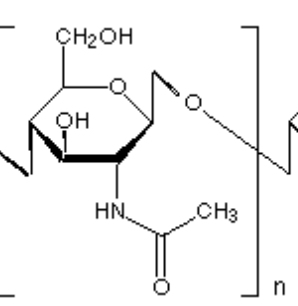

8

$$
\text { Lignin }
$$

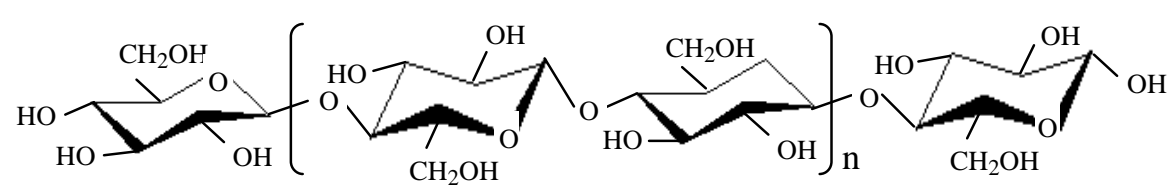

\section{Cellulose}

R1: mostly $\mathrm{OCH}_{3}$, H or other unit R2: mostly $\mathrm{OCH}_{3}$ R3: mostly $\mathrm{OH}$ or other unit R4: mostly other unit

FIGURE S1. Chemical structures of lignin, chitin and cellulose (from the company from which the samples were purchased).

\footnotetext{
* Corresponding authors (Baoshan Xing). Tel: (413) 545-5212; Fax: (413) 545-3958; Email: bx@ pssci.umass.edu
} 
A
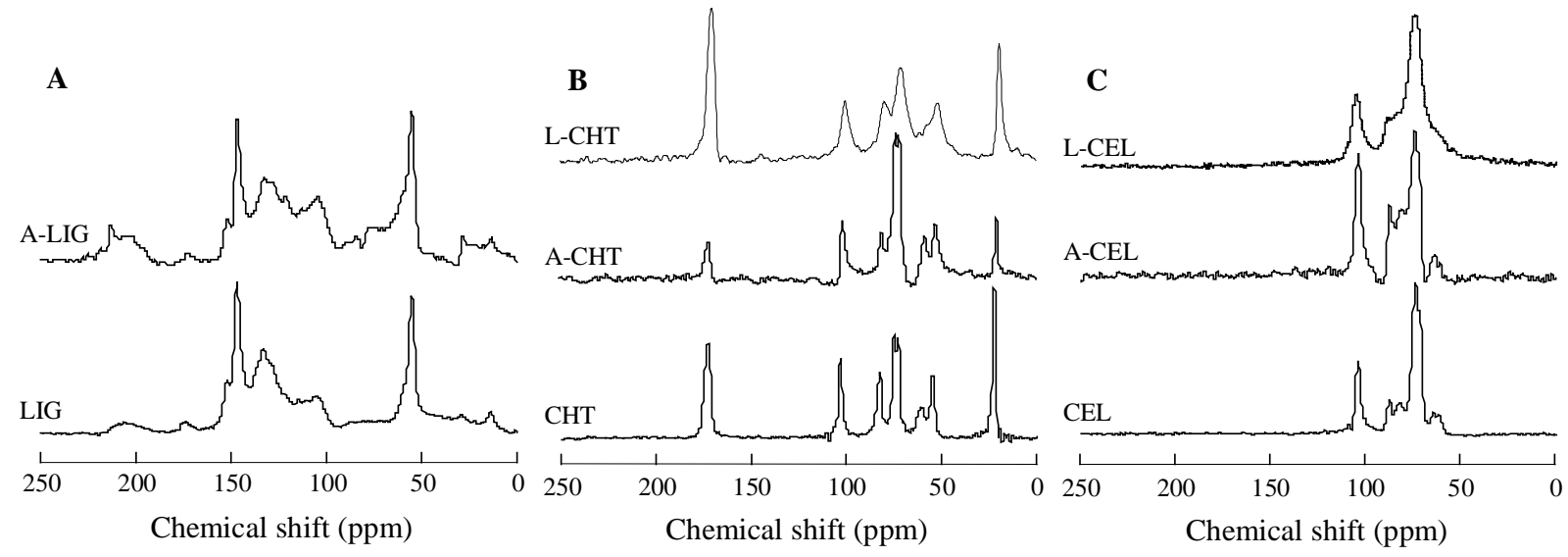

FIGURE S2. Solid-state ${ }^{13} \mathrm{C}$ NMR spectra of lignin, chitin and cellulose, acetone-treated lignin, chitin and cellulose as well as lignin-coated chitin and cellulose. A strong peak at $22 \mathrm{ppm}$ for CHT showed the high abundance of $\mathrm{CH}_{3}$ groups (2), while short aliphatic chains of LIG appeared at 14 and $23 \mathrm{ppm}$. No alkyl C was observed for CEL. The carbonyl groups in CHT were illustrated by a strong peak at $174 \mathrm{ppm}$ (2).

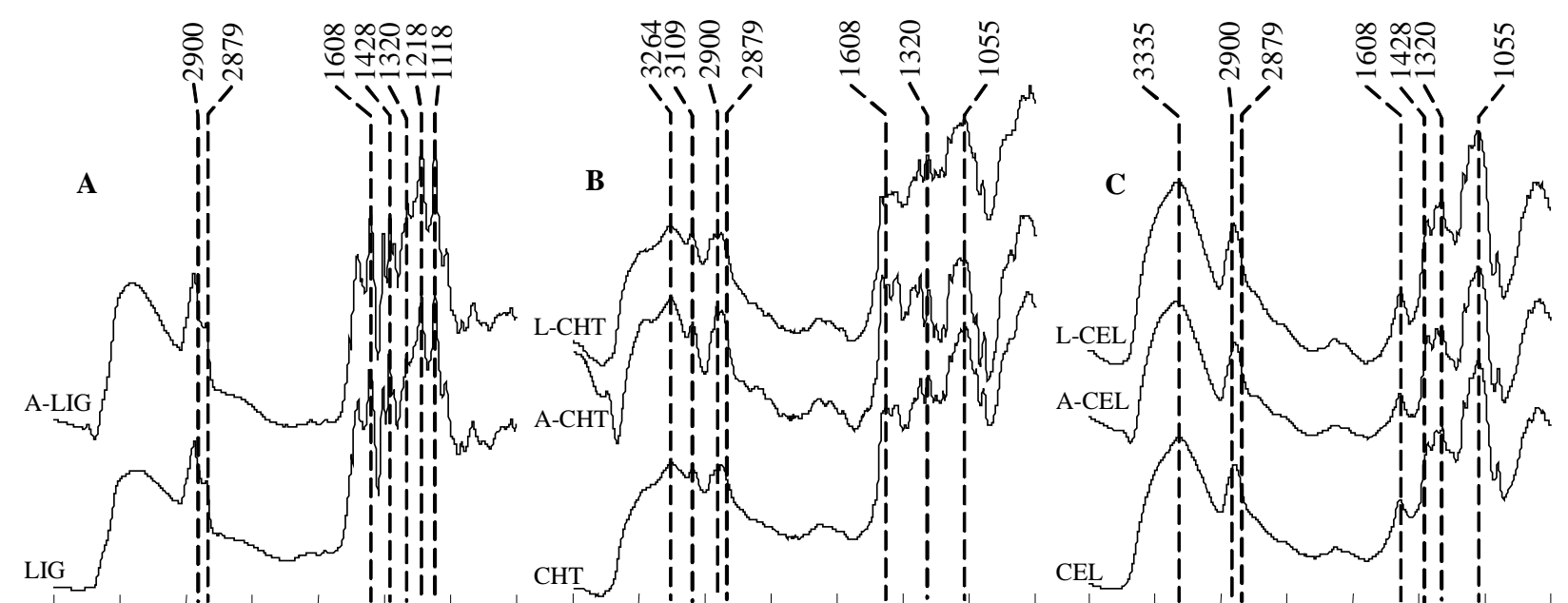

$4000350030002500200015001000 \quad 500400035003000250020001500 \quad 1000 \quad 5004000 \quad 3500 \quad 3000 \quad 2500 \quad 2000 \quad 1500 \quad 1000 \quad 500$ Wavenumber $\left(\mathrm{cm}^{-1}\right)$

Wavenumber $\left(\mathrm{cm}^{-1}\right)$

Wavenumber $\left(\mathrm{cm}^{-1}\right)$

FIGURE S3. DRIFT spectra of lignin, chitin and cellulose, acetone-treated lignin, chitin and cellulose as well as lignin-coated chitin and cellulose. The broad band at $3335 \mathrm{~cm}^{-1}$ for CEL was assigned to OH stretching. Peaks at 3264 and $3109 \mathrm{~cm}^{-1}$ for CHT were assigned to $\mathrm{NH}$ and $\mathrm{OH}$ stretching. No clear change of these two peaks after LIG coating was observed, due to very low N content of LIG (Table 1). The peaks at 1320, 1218, 1118 and 1055 $\mathrm{cm}^{-1}$ were attributed to $\mathrm{C}-\mathrm{C}, \mathrm{C}-\mathrm{O}$ and $\mathrm{C}-\mathrm{O}-\mathrm{C}$ stretching. LIG-coating did not change these peaks for CHT and

61 CEL. 

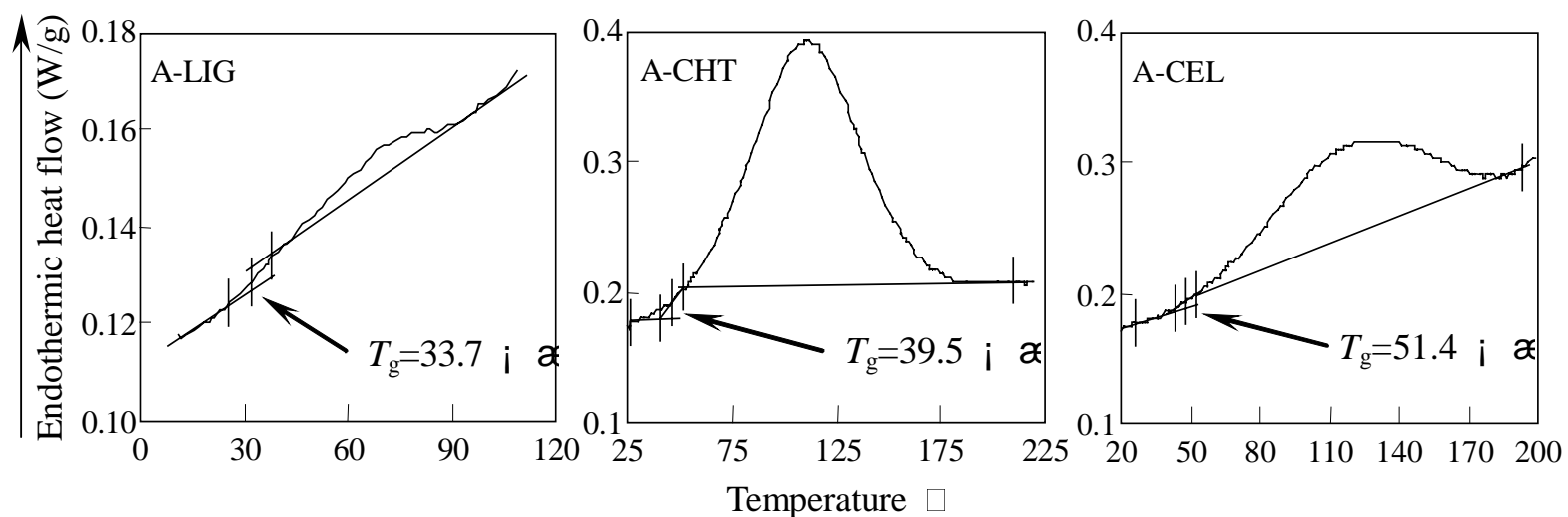

Temperature

FIGURE S4. Calorimetric analysis of the glass transitions of acetone-treated lignin, chitin and cellulose.
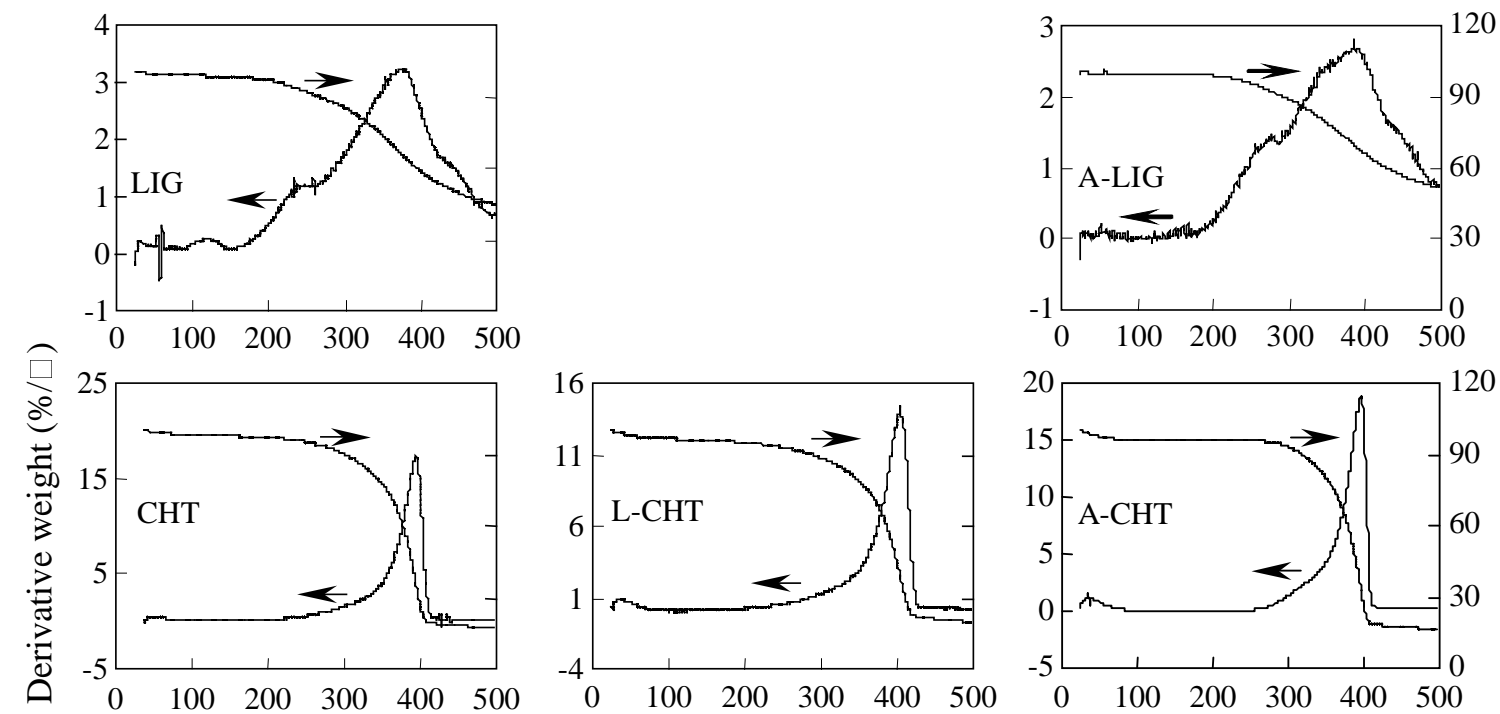

(1)

100
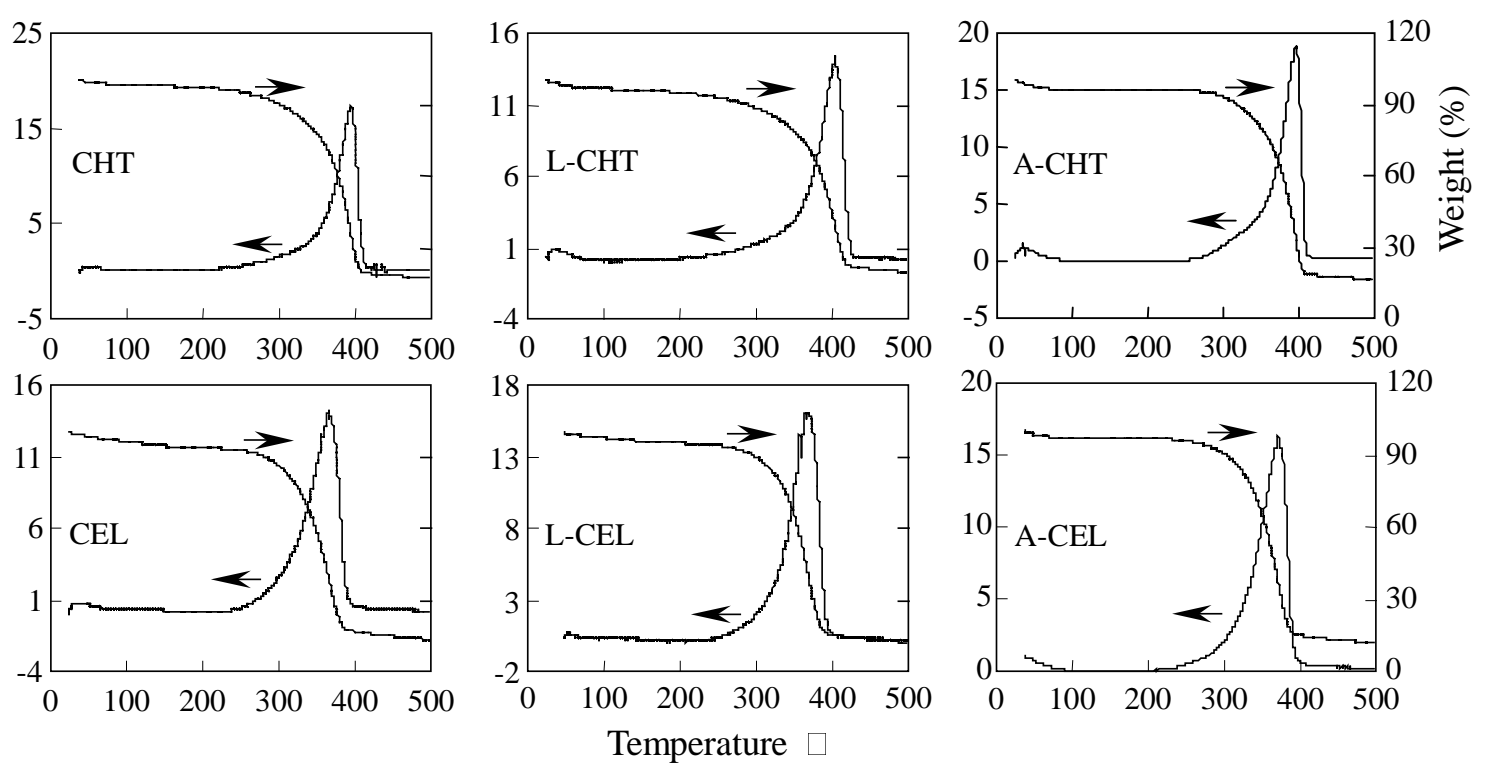

FIGURE S5. Thermal gravimetric analysis (TGA) scan of original lignin (LIG), chitin (CHT) and cellulose

101

(CEL), acetone-treated lignin (A-LIG), chitin (A-CHT) and cellulose (A-CEL), as well as lignin coated chitin 102 (L-CHT) and cellulose (L-CEL). 


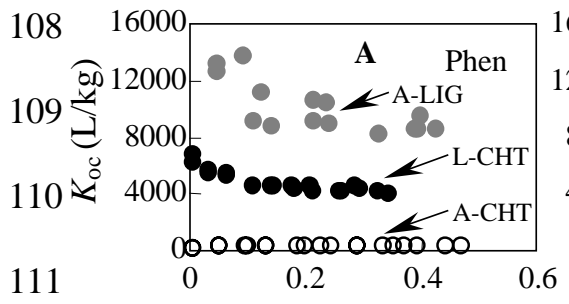

112

113

114

115

116

117

118

119

120

121

122

123

124 LIG-coated CHT and CEL.

5

7

\section{Literature cited} 237-241.
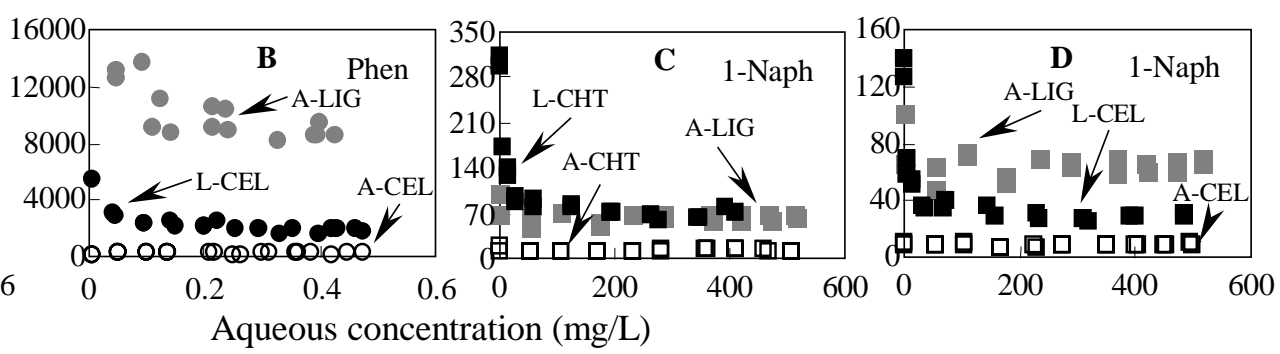

Aqueous concentration $(\mathrm{mg} / \mathrm{L})$

FIGURE S6. $K_{\mathrm{oc}}$ value comparison of Phen and 1-Naph sorption by acetone-treated LIG, CHT and CEL, and

(1) Wang, X. L.; Yang, K.; Tao, S.; Xing, B. S. Sorption of aromatic organic contaminants by biopolymers: Effects of pH, copper (II) complexation and cellulose coating. Environ. Sci. Technol. 2007, 40, 185-191.

(2) Majtán, J.; Bíliková, K.; Markovič, O.; Gróf, J.; Kogan, G.; Šimúth, J. Isolation and characterization of chitin from bumblebee (Bombus terrestris). International Journal of Biological Macromolecules 2007, 40, 